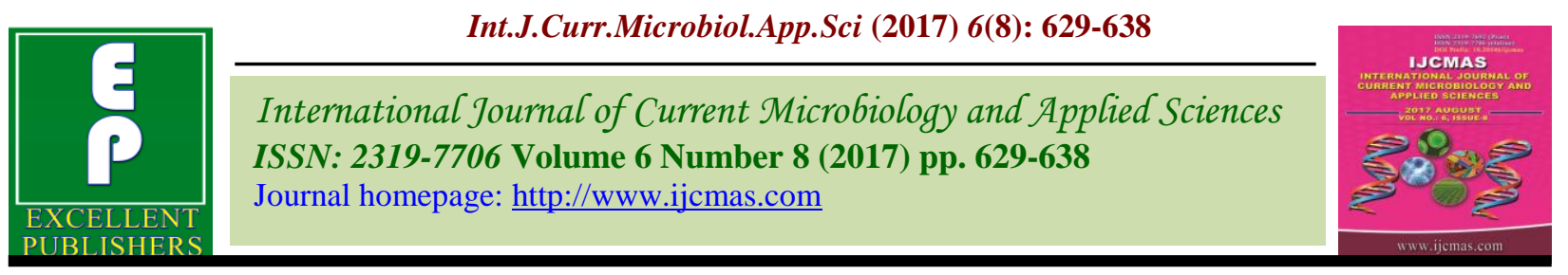

Original Research Article https://doi.org/10.20546/ijcmas.2017.608.080

\title{
Effect of Seed Size, Pre Sowing Treatment and Potting Mixture on the Seedling Growth of Parkia roxburghii G. Don Seeds
}

\author{
Aruna Rana ${ }^{1}$, Chanu Langlentombi Leishangthem ${ }^{1^{*}}$, Haseena Kadiri ${ }^{2}$ and \\ Benjamin Ng Nakho Ziipoa ${ }^{3}$
}

${ }^{1}$ Dr Yashwant Singh Parmar University of Horticulture and Forestry, Nauni-173230, Solan, Himachal Pradesh, India

${ }^{2}$ Department of Forestry and Environmental Science, Gandhi Krishi Vigyan Kendra,

University of Agricultural Sciences, Bangalore, Karnataka, India

${ }^{3}$ Wildlife Institute of India, Chandrabani, Dehradun 248001, Uttarakhand, India

*Corresponding author

\section{A B S T R A C T}

Keywords

Seed size, Potting mixture, Pre sowing treatment, Seedling growth.

Article Info

Accepted:

04 June 2017

Available Online:

10 August 2017
The experiment was conducted at Dr YS Parmar University of Horticulture and Forestry, Nauni, Solan. The seeds were graded into small $\left(\mathrm{L}_{1}\right)$, medium $\left(\mathrm{L}_{2}\right)$ and large size $\left(\mathrm{L}_{3}\right)$ on the basis of length. The seeds subjected to seven pre sowing treatments were sown in potting mixture consisting of soil, sand and FYM in four different ratios. The experiment was laid out in nursery conditions in randomized block design (RBD factorial) with three replications to determine most suitable seed size, pre sowing treatment and potting mixture for seedling growth parameters of Parkia roxburghii. It was evident from the study that large size seeds $\left(\mathrm{L}_{3}\right)$ excelled all other grades in all seedling growth parameters. The seeds treated with boiling water and soaking for $24 \mathrm{hrs}\left(\mathrm{T}_{5}\right)$ registered significantly maximum seedling growth parameters. The seeds sown in potting mixture consisting of soil, sand and FYM in ratio 1:2:4 $\left(\mathrm{M}_{4}\right)$ registered significantly maximum seedling growth parameters.

\section{Introduction}

Tree bean, Parkia roxburghii G. Don, belongs to the family Leguminaceae and subfamily Mimosoidae, is a lesser known nutritious, leguminous tree which grows luxuriantly in North East India and South East Asia. It is also known as yongchak in Manipuri and Zongtan in Mizoram. It is distributed in India, Bangladesh, Burma (Myanmar), Thailand and the Malaysian region. The various plant parts like pods, seeds and flowers are consumed by the people of Mizoram, Manipur and
Nagaland, raw or in various preparations such as salads and curries. It is a valued diet supplement and different edible parts of the plant are used medicinally. The pods are known to cure stomach disorders and regulate liver functions. The oil extract of the plant possesses insecticidal properties and the woods can be used as a source of paper pulp (Thangjam and Maibam, 2006). The tree bean being a fast-growing leguminous species with multiple uses is considered suitable for 
reclamation of abandoned jhum land. Being a legume it would also help enrich the soil through nitrogen fixation. It is valued for its subsistence products and as an important source of cash income (Rocky and Sahoo, 2002). Moreover, the tree provides fuel wood for the local people of these states. Hence, the planting of these trees should be promoted in India for conservation of natural resources and improving the livelihood of hill farmers in the region.

Despite a variety of uses, unfortunately the tree bean plants are under threat due to overharvesting of pods and seeds. The seeds of Parkia have a low percentage of germination in the field and the dormancy of its seeds has been attributed to the presence of inhibitor as well as the impermeable seed coat. A prerequisite in any planting programme is an assured supply of seeds (FAO, 1995). Seed is such a key element in plant production that it exercises a profound influence on the success or failure of both artificial and natural regeneration and it is of fundamental importance since both artificial and natural regeneration start with it. The bigger seed size and more seed weight contains more amount of reserve food material in contrast to the germinating seedlings of smaller seed size and lesser seed weight which have only small quantity of reserve food material to bank upon before it is able to manufacture its own food material by process of photosynthesis (Athaya, 1985). Thus, seedlings from large sized fruit could establish in wider range of environmental conditions. The hard and impermeable seed coat prevents the entry of moisture and gaseous exchange delaying germination. So, pre-sowing treatments are used not only to ensure the rapid germination but it also decreases labour, cost and time for nursery production. The better growth of the seedling is the result of available nutrients during the seedling growth period and these nutrients can be supplied either by chemical fertilizers, organic manures or some other means. The most important propagation media are soils, sand and FYM. It has been seen that continuous use of chemical fertilizer posed a serious threat to the environment and led to residual effect in food product. Organic manure is considered imperative for human and animal health. Most commonly used organic manure is FYM in which cattle dung constitute the major source of nutrients and the application of seed treatments and FYM as soil supplement may improve the performance of this species but knowledge and information about the response of this species to organic manure are scarce. No systematic work has been done on seed size and seedling growth parameters of Parkia roxburghii so far thus hampering the afforestation program of this valuable species. As a result of these factors, it is necessary to standardise the seed size, pre sowing treatment and potting mixture for producing quality seedlings.

\section{Materials and Methods}

The experiment was conducted at the Majhgaon nursery of the Department of Silviculture and Agroforestry, Dr YS Parmar University of Horticulture and Forestry, located at $30^{\circ} 51^{\prime} \mathrm{N}$ latitude and $76^{\circ} \quad 1^{\prime} \mathrm{E}$ longitude. The climate of Nauni area ranges from sub-tropical to sub-temperate and experiences $850 \mathrm{~mm}$ to $1300 \mathrm{~mm}$ precipitation, major part of which is received during July and August. During the study period maximum rainfall $361 \mathrm{~mm}$ was received during July. May- June was the hottest months, whereas December and January were coldest months.

\section{Material collection}

The seeds were obtained from Manipur during month of July, 2014. Diseased seeds 
were discarded. The seeds with no visible sign of injury were graded into three categories based on length of seeds as given below:

\begin{tabular}{|l|l|}
\hline Category & Size \\
\hline $\mathrm{L}_{1}$ & Small $(<1.6 \mathrm{~cm})$ \\
\hline $\mathrm{L}_{2}$ & Medium $(1.6-1.8 \mathrm{~cm})$ \\
\hline $\mathrm{L}_{3}$ & Large $(>1.8 \mathrm{~cm})$ \\
\hline
\end{tabular}

\section{Pre-sowing treatments}

The graded seeds were subjected to seven different pre- sowing treatments:

\begin{tabular}{|l|l|}
\hline Code & Treatment \\
\hline $\mathrm{T}_{1}$ & Control \\
\hline $\mathrm{T}_{2}$ & $\begin{array}{l}\text { Soaking in water at room temperature } \\
\text { for } 24 \mathrm{hrs}\end{array}$ \\
\hline $\mathrm{T}_{3}$ & $\begin{array}{l}\text { Soaking in water at room temperature } \\
\text { for } 48 \mathrm{hrs}\end{array}$ \\
\hline $\mathrm{T}_{4}$ & $\begin{array}{l}\text { Boiling water treatment and soaking for } \\
12 \text { hrs }\end{array}$ \\
\hline $\mathrm{T}_{5}$ & $\begin{array}{l}\text { Boiling water treatment and soaking for } \\
24 \text { hrs }\end{array}$ \\
\hline $\mathrm{T}_{6}$ & $\begin{array}{l}\text { Conc. } \mathrm{H}_{2} \mathrm{SO}_{4} \quad 2 \text { min. dip and then } \\
\text { washing }\end{array}$ \\
\hline $\mathrm{T}_{7}$ & $\begin{array}{l}\text { Conc. } \mathrm{H}_{2} \mathrm{SO}_{4} \quad 4 m i n . \text { dip and then } \\
\text { washing }\end{array}$ \\
\hline
\end{tabular}

\section{Potting mixture (v/v)}

Potting mixture used to fill poly bags consisted of soil, sand and farmyard manure (FYM) in four different proportion as given below:

\begin{tabular}{|l|l|l|}
\hline Code & Description & Ratio \\
\hline$M_{1}$ & Soil: Sand: FYM & $1: 1: 1$ \\
\hline$M_{2}$ & Soil: Sand: FYM & $1: 2: 2$ \\
\hline$M_{3}$ & Soil: Sand: FYM & $1: 2: 3$ \\
\hline$M_{4}$ & Soil: Sand: FYM & $1: 2: 4$ \\
\hline
\end{tabular}

\section{Germination}

The seeds were sown in different potting mixture during august, 2014 at the polyhouse in a randomised block design (RBD). A sample of 150 seeds per treatment was taken for conducting the experiment.

\section{Seedling growth studies}

For seedling growth studies, four seedlings per replication were randomly selected and carefully uprooted without breaking the roots at the end of growing season. The following attributes were measured.

\section{Seedling length $(\mathrm{cm})$}

Seedling length was recorded in centimetres using a scale from root tip to the top/ tip of shoot.

Seedling length $=$ Shoot length + Root length

\section{Root length (cm)}

The length of tap root was recorded in centimetres using measuring scale by placing it horizontally on the ground.

\section{Shoot length $(\mathrm{cm})$}

It was measured with the help of meter scale from leading shoot tip to the collar region of the seedling at the ground surface.

\section{Collar diameter $(\mathbf{m m})$}

Collar diameter of seedling was measured in millimetres $(\mathrm{mm})$ by using digital calliper.

\section{Statistical analysis}

The data obtained from the experiment was subjected to statistical analysis as per the methods described (Gomez and Gomez, 1984). 


\section{Results and Discussion}

Effect of seed size, pre sowing treatment and potting mixture on Parkia roxburghii seedling growth parameters

Table 1 shows that the seed size, pre sowing treatment, potting mixture and their interaction had a significant effect on seedling growth parameters of Parkia roxburghii.

\section{Root length}

The data shows that seed size exerted significant effect on root length. The significantly maximum root length $(17.14 \mathrm{~cm})$ was recorded in seedlings from large size seeds $\left(\mathrm{L}_{3}\right)$ and minimum value $(11.11 \mathrm{~cm})$ was recorded from small size seeds $\left(\mathrm{L}_{1}\right)$. Among the pre sowing treatments, maximum $(16.77 \mathrm{~cm})$ root length was recorded in $T_{5}$ which was statistically at par with $\mathrm{T}_{6}(15.64$ $\mathrm{cm})$ while the minimum $(10.64 \mathrm{~cm})$ root length was recorded in $T_{1}$. The seedlings grown in potting mixture $\mathrm{M}_{4}$ showed maximum $(16.57 \mathrm{~cm})$ root length while minimum $(11.35 \mathrm{~cm})$ root length was shown by seedlings grown in potting mixture $\mathrm{M}_{1}$.

\section{Shoot length}

Seed size had a significant effect on shoot length. The maximum $(18.58 \mathrm{~cm})$ shoot length was recorded in seedlings from large size seeds $\left(\mathrm{L}_{3}\right)$ and significantly minimum value $(12.67 \mathrm{~cm})$ was observed in small size seeds $\left(\mathrm{L}_{1}\right)$. Among the pre sowing treatments, maximum shoot length was recorded in $T_{5}$ which was statistically at par with $\mathrm{T}_{6}$ and minimum $(12.64 \mathrm{~cm})$ shoot length was recorded in $\mathrm{T}_{1}$ which was statistically at par with $\mathrm{T}_{2}$. The seedlings grown in potting mixture $\mathrm{M}_{4}$ showed maximum $(18.02 \mathrm{~cm})$ shoot length while minimum $(12.97 \mathrm{~cm})$ shoot length was observed in seedlings grown in potting mixture $\mathrm{M}_{1}$.

\section{Seedling length}

The data shows that the seed size, pre sowing treatment, potting mixture had a significant effect on seedling length. The maximum seedling length $(35.72 \mathrm{~cm})$ was obtained when large size seeds $\left(\mathrm{L}_{3}\right)$ were used for sowing. The minimum $(23.78 \mathrm{~cm})$ seedling length was recorded in small size seeds $\left(\mathrm{L}_{1}\right)$. Among the pre sowing treatments maximum seedling length was recorded in $\mathrm{T}_{5}(34.96 \mathrm{~cm})$ and minimum in $\mathrm{T}_{1}(23.28 \mathrm{~cm})$. The seedlings grown in potting mixture $\mathrm{M}_{4}$ showed maximum seedling length $(34.59 \mathrm{~cm})$ while seedlings grown in potting mixture $\mathrm{M}_{1}$ showed minimum seedling height $(24.32 \mathrm{~cm})$.

\section{Collar diameter}

Seed size and potting mixture had a significant effect on collar diameter of the seedlings while the effect of pre sowing treatment was non-significant. Among the seed size, significantly maximum $(4.62 \mathrm{~mm})$ collar diameter was recorded in $\mathrm{L}_{3}$ and significantly minimum $(3.87 \mathrm{~mm})$ collar diameter was recorded in $\mathrm{L}_{1}$. Though nonsignificant, maximum collar diameter (4.62 $\mathrm{mm})$ was recorded in $\mathrm{T}_{5}$ and minimum in $\mathrm{T}_{1}$ $(3.92 \mathrm{~mm})$. The maximum $(4.70 \mathrm{~mm})$ collar diameter was recorded in potting mixture $\mathrm{M}_{4}$ while minimum $(3.33 \mathrm{~mm})$ collar diameter was recorded in potting mixture $\mathrm{M}_{1}$.

\section{Effect of seed size and potting mixture interaction (LxM) on Parkia roxburghii seedling growth parameters}

It is evident from table 2 that seed size and potting mixture had a significant effect on seedling growth parameters of Parkia roxburghii. In the interaction between seed size and potting mixture (LxM), maximum $(19.93 \mathrm{~cm})$ root length was found in $\mathrm{L}_{3} \mathrm{M}_{4}$ and minimum root length $(8.14 \mathrm{~cm})$ was recorded in $\mathrm{L}_{1} \mathrm{M}_{1}$ which was statistically at par with 
$\mathrm{L}_{1} \mathrm{M}_{2}(10.17 \mathrm{~cm})$. The maximum $(21.02 \mathrm{~cm})$ shoot length was found in $\mathrm{L}_{3} \mathrm{M}_{4}$ while minimum shoot length $(9.58 \mathrm{~cm})$ was recorded in $\mathrm{L}_{1} \mathrm{M}_{1}$. The maximum $(40.95 \mathrm{~cm})$ seedling length was found in $\mathrm{L}_{3} \mathrm{M}_{4}$ while the minimum seedling length $17.72 \mathrm{~cm}$ was recorded in $\mathrm{L}_{1} \mathrm{M}_{1}$. The maximum $(5.11 \mathrm{~mm})$ collar diameter was recorded in $\mathrm{L}_{3} \mathrm{M}_{4}$ which was statistically at par with $\mathrm{L}_{3} \mathrm{M}_{3}(4.67 \mathrm{~mm})$ while minimum $(3.30 \mathrm{~mm})$ collar diameter was recorded in $\mathrm{L}_{1} \mathrm{M}_{1}$ which was found to be statistically at par with $\mathrm{L}_{1} \mathrm{M}_{2}(3.74 \mathrm{~mm})$ and $\mathrm{L}_{2} \mathrm{M}_{1}$ (3.92 mm).

\section{Effect of pre sowing treatment and potting} mixture interaction (TxM) on Parkia roxburghii seedling growth parameters

The interaction of pre sowing treatments and potting mixture had a significant effect on seedling growth parameters of Parkia roxburghii, as observed from table 3 . In the interaction between pre sowing treatment and potting mixture $(\mathrm{TxM})$, maximum $(19.58 \mathrm{~cm})$ root length was recorded in $\mathrm{T}_{5} \mathrm{M}_{4}$ which was statistically at par with $\mathrm{T}_{5} \mathrm{M}_{3}(17.33 \mathrm{~cm})$, $\mathrm{T}_{4} \mathrm{M}_{4}(16.47 \mathrm{~cm}), \mathrm{T}_{6} \mathrm{M}_{4}(18.61 \mathrm{~cm})$ and $\mathrm{T}_{7} \mathrm{M}_{4}$ $(17.89 \mathrm{~cm})$ while significantly minimum $(7.48$ $\mathrm{cm})$ root length was recorded in $\mathrm{T}_{1} \mathrm{M}_{1}$ which was found to be statistically at par with $\mathrm{T}_{1} \mathrm{M}_{2}$ $(9.31 \mathrm{~cm}), \mathrm{T}_{2} \mathrm{M}_{1}(9.39 \mathrm{~cm})$ and $\mathrm{T}_{3} \mathrm{M}_{1}(10.73$ $\mathrm{cm})$.

Similarly, the maximum $(21.79 \mathrm{~cm})$ shoot length was recorded in $\mathrm{T}_{5} \mathrm{M}_{4}$ which was statistically at par with $\mathrm{T}_{5} \mathrm{M}_{3}(19.02 \mathrm{~cm})$, $\mathrm{T}_{6} \mathrm{M}_{4}(20.10 \mathrm{~cm})$ and $\mathrm{T}_{7} \mathrm{M}_{4}(19.01 \mathrm{~cm})$ while significantly minimum $10.06 \mathrm{~cm}$ shoot length was recorded in $\mathrm{T}_{1} \mathrm{M}_{1}$ which was found to be statistically at par with $\mathrm{T}_{1} \mathrm{M}_{2}(11.88 \mathrm{~cm})$, $\mathrm{T}_{2} \mathrm{M}_{1}(11.60 \mathrm{~cm}), \mathrm{T}_{3} \mathrm{M}_{1}(12.33 \mathrm{~cm})$ and $\mathrm{T}_{4} \mathrm{M}_{1}$ $(12.79 \mathrm{~cm})$. The maximum $(41.37 \mathrm{~cm})$ seedling length was recorded in $\mathrm{T}_{5} \mathrm{M}_{4}$ which was statistically at par with $\mathrm{T}_{5} \mathrm{M}_{3}(36.36 \mathrm{~cm})$,
$\mathrm{T}_{6} \mathrm{M}_{4}(38.71 \mathrm{~cm})$ and $\mathrm{T}_{7} \mathrm{M}_{4}(36.90 \mathrm{~cm})$ while minimum $(17.53 \mathrm{~cm})$ seedling length was recorded in $\mathrm{T}_{1} \mathrm{M}_{1}$ which was found to be statistically at par with $\mathrm{T}_{1} \mathrm{M}_{2}(21.19 \mathrm{~cm})$, $\mathrm{T}_{2} \mathrm{M}_{1}(20.99 \mathrm{~cm})$ and $\mathrm{T}_{3} \mathrm{M}_{1}(23.07 \mathrm{~cm})$. Though non-significant maximum $(5.03 \mathrm{~mm})$ collar diameter was recorded $\mathrm{T}_{5} \mathrm{M}_{4}$ while minimum $(3.33 \mathrm{~mm})$ collar diameter was recorded in $\mathrm{T}_{1} \mathrm{M}_{1}$.

\section{Effect of seed size on seedling growth parameters under nursery conditions}

The seed size exerted significant effect on Parkia roxburghii seedling growth parameters under nursery conditions. Large size seeds $\left(\mathrm{L}_{3}\right)$ registered significantly highest root length $(17.14 \mathrm{~cm})$, shoot length $(18.58 \mathrm{~cm})$, seedling length $(35.72 \mathrm{~cm})$ and collar diameter $(4.62 \mathrm{~mm})$. This may be ascribed to the fact that large size seed contained more nutrient reserve, energy pool and biochemical contents which might have stimulated better seedling growth. The small size seeds accounted for lesser food material and biochemical contents leading to poor seedling growth. The results are thus, in agreement with Owoh et al., (2011), who reported that large size seeds produced maximum seedling length and collar diameter in Gmelina arborea. Similarly, Mwase and Mvula (2011) revealed that large size seeds produced highest seedling length and diameter growth in Bauhinia thonningii. Similar growth characteristics for large size seeds has been reported by several researchers in many species. Maximum height and collar diameter in Jatropha curcas (Singh and Saxena, 2009), shoot length and root length in Azadirachta indica (Uniyal et al., 2007), shoot and root growth in Sapindus emerginatus (Venkatesh et al., 2010) and root length and shoot length in Hardwickia binate (Ponnammal et al., 1993). 
Table.1 Effect of seed size, pre sowing treatment and potting mixture on seedling growth Parameters under nursery conditions

\begin{tabular}{|c|c|c|c|c|}
\hline Treatments & $\begin{array}{l}\text { Root length } \\
(\mathrm{cm})\end{array}$ & $\begin{array}{l}\text { Shoot length } \\
(\mathrm{cm})\end{array}$ & \begin{tabular}{|l} 
Seedling height \\
$(\mathrm{cm})$
\end{tabular} & \begin{tabular}{|l} 
Collar diameter \\
$(\mathrm{mm})$
\end{tabular} \\
\hline \multicolumn{5}{|c|}{ Effect of seed size } \\
\hline $\mathbf{L}_{1}$ & 11.11 & 12.67 & 23.78 & 3.87 \\
\hline $\mathbf{L}_{2}$ & 13.68 & 15.27 & 28.95 & 4.37 \\
\hline $\mathbf{L}_{3}$ & 17.14 & 18.58 & 35.72 & 4.62 \\
\hline SEm \pm & 0.389 & 0.343 & 0.598 & 0.065 \\
\hline $\mathrm{CD}_{(0.05)}$ & 1.08 & 0.95 & 1.95 & 0.183 \\
\hline \multicolumn{5}{|c|}{ Effect of pre sowing treatments } \\
\hline $\mathbf{T}_{1}$ & 10.64 & 12.64 & 23.28 & 3.92 \\
\hline $\mathbf{T}_{2}$ & 12.34 & 14.06 & 26.40 & 4.10 \\
\hline $\mathbf{T}_{3}$ & 13.32 & 14.89 & 28.21 & 4.20 \\
\hline $\mathbf{T}_{4}$ & 14.17 & 15.37 & 29.54 & 4.30 \\
\hline $\mathbf{T}_{5}$ & 16.77 & 18.19 & 34.96 & 4.62 \\
\hline $\mathbf{T}_{6}$ & 15.64 & 17.20 & 32.84 & 4.50 \\
\hline $\mathbf{T}_{7}$ & 14.98 & 16.19 & 31.16 & 4.37 \\
\hline SEm \pm & 0.59 & 0.52 & 0.91 & 0.11 \\
\hline $\mathrm{CD}_{(0.05)}$ & 1.66 & 1.45 & 1.45 & NS \\
\hline \multicolumn{5}{|c|}{ Effect of potting mixture } \\
\hline $\mathbf{M}_{1}$ & 11.35 & 12.97 & 24.32 & 3.83 \\
\hline $\mathbf{M}_{2}$ & 13.05 & 14.50 & 27.55 & 4.16 \\
\hline $\mathbf{M}_{3}$ & 14.93 & 16.55 & 31.48 & 4.45 \\
\hline $\mathbf{M}_{4}$ & 16.57 & 18.02 & 34.59 & 4.70 \\
\hline SEm \pm & 0.45 & 0.39 & 0.69 & 0.075 \\
\hline $\mathrm{CD}_{(\mathbf{0 . 0 5})}$ & 1.25 & 1.09 & 2.27 & 0.21 \\
\hline
\end{tabular}

L: Seed size category, T: Pre sowing treatments, M: Potting Mixture

Table.2 Interaction effect of seed size and potting mixture (LxM) on seedling growth parameters under nursery conditions

\begin{tabular}{|c|c|c|c|c|}
\hline $\begin{array}{c}\text { Interaction } \\
(\mathbf{L x M})\end{array}$ & $\begin{array}{c}\text { Root length } \\
(\mathbf{c m})\end{array}$ & $\begin{array}{c}\text { Shoot length } \\
(\mathbf{c m})\end{array}$ & $\begin{array}{c}\text { Seedling height } \\
(\mathbf{c m})\end{array}$ & $\begin{array}{c}\text { Collar diameter } \\
(\mathbf{m m})\end{array}$ \\
\hline $\mathbf{L}_{\mathbf{1}} \mathbf{M}_{\mathbf{1}}$ & 8.14 & 9.58 & 17.72 & 3.29 \\
\hline $\mathbf{L}_{\mathbf{1}} \mathbf{M}_{\mathbf{2}}$ & 10.17 & 11.58 & 21.75 & 3.74 \\
\hline $\mathbf{L}_{\mathbf{1}} \mathbf{M}_{\mathbf{3}}$ & 12.13 & 14.00 & 26.14 & 4.16 \\
\hline $\mathbf{L}_{\mathbf{1}} \mathbf{M}_{\mathbf{4}}$ & 13.99 & 15.53 & 29.52 & 4.29 \\
\hline $\mathbf{L}_{\mathbf{2}} \mathbf{M}_{\mathbf{1}}$ & 11.07 & 12.73 & 23.79 & 3.92 \\
\hline $\mathbf{L}_{\mathbf{2}} \mathbf{M}_{\mathbf{2}}$ & 12.87 & 14.41 & 27.28 & 4.33 \\
\hline $\mathbf{L}_{\mathbf{2}} \mathbf{M}_{\mathbf{3}}$ & 14.99 & 16.44 & 31.43 & 4.51 \\
\hline $\mathbf{L}_{\mathbf{2}} \mathbf{M}_{\mathbf{4}}$ & 15.80 & 17.51 & 33.31 & 4.71 \\
\hline $\mathbf{L}_{\mathbf{3}} \mathbf{M}_{\mathbf{1}}$ & 14.84 & 16.59 & 31.44 & 4.26 \\
\hline $\mathbf{L}_{\mathbf{3}} \mathbf{M}_{\mathbf{2}}$ & 16.11 & 17.50 & 33.62 & 4.42 \\
\hline $\mathbf{L}_{\mathbf{3}} \mathbf{M}_{\mathbf{3}}$ & 17.69 & 19.20 & 36.89 & 4.67 \\
\hline $\mathbf{L}_{\mathbf{3}} \mathbf{M}_{\mathbf{4}}$ & 19.93 & 21.02 & 40.95 & 5.11 \\
\hline $\mathbf{S E m}_{\mathbf{C}}$ & 1.03 & 0.91 & $\mathbf{1 . 5 8}$ & 0.17 \\
$\mathbf{C D}_{\mathbf{( 0 . 0 5}}$ & 2.17 & 1.74 & $\mathbf{3 . 9 3}$ & 0.62 \\
\hline
\end{tabular}

L: Seed size category, M: Potting Mixture 
Table.3 Interaction effect of pre sowing treatment and potting mixture (TxM) on seedling Growth parameters under nursery conditions

\begin{tabular}{|c|c|c|c|c|}
\hline $\begin{array}{c}\text { Interaction } \\
(\mathbf{T x M})\end{array}$ & $\begin{array}{l}\text { Root length } \\
(\mathrm{cm})\end{array}$ & $\begin{array}{c}\text { Shoot length } \\
\text { (cm) }\end{array}$ & $\begin{array}{l}\text { Seedling height } \\
(\mathrm{cm})\end{array}$ & $\begin{array}{c}\text { Collar diameter } \\
(\mathrm{mm})\end{array}$ \\
\hline$T_{1} M_{1}$ & 7.48 & 10.06 & 17.53 & 3.33 \\
\hline$T_{1} M_{2}$ & 9.31 & 11.88 & 21.19 & 3.90 \\
\hline$T_{1} M_{3}$ & 12.37 & 13.96 & 26.32 & 4.15 \\
\hline$T_{1} M_{4}$ & 13.89 & 14.68 & 28.08 & 4.29 \\
\hline $\mathbf{T}_{2} \mathbf{M}_{1}$ & 9.39 & 11.60 & 20.99 & 3.60 \\
\hline $\mathbf{T}_{2} \mathbf{M}_{2}$ & 11.80 & 13.39 & 25.19 & 3.93 \\
\hline $\mathbf{T}_{2} \mathbf{M}_{3}$ & 13.61 & 15.20 & 28.81 & 4.38 \\
\hline$T_{2} M_{4}$ & 14.56 & 16.06 & 30.61 & 4.49 \\
\hline$T_{3} M_{1}$ & 10.73 & 12.33 & 23.07 & 3.69 \\
\hline$T_{3} M_{2}$ & 12.51 & 14.07 & 26.58 & 4.04 \\
\hline$T_{3} M_{3}$ & 14.50 & 16.17 & 30.67 & 4.41 \\
\hline$T_{3} M_{4}$ & 15.52 & 17.01 & 32.53 & 4.64 \\
\hline$T_{4} M_{1}$ & 11.72 & 12.79 & 24.51 & 3.88 \\
\hline $\mathbf{T}_{4} \mathbf{M}_{2}$ & 13.38 & 14.70 & 28.08 & 4.13 \\
\hline $\mathbf{T}_{4} \mathbf{M}_{3}$ & 15.12 & 16.52 & 31.64 & 4.44 \\
\hline $\mathbf{T}_{4} \mathbf{M}_{4}$ & 16.47 & 17.48 & 33.94 & 4.74 \\
\hline$T_{5} M_{1}$ & 14.31 & 15.23 & 29.54 & 4.24 \\
\hline $\mathbf{T}_{5} \mathbf{M}_{2}$ & 15.84 & 16.73 & 32.58 & 4.51 \\
\hline$T_{5} M_{3}$ & 17.33 & 19.02 & 36.36 & 4.71 \\
\hline$T_{5} M_{4}$ & 19.58 & 21.79 & 41.37 & 5.03 \\
\hline$T_{6} M_{1}$ & 13.17 & 14.92 & 28.09 & 4.09 \\
\hline$T_{6} M_{2}$ & 14.51 & 15.63 & 30.14 & 4.37 \\
\hline$T_{6} M_{3}$ & 16.26 & 18.16 & 34.41 & 4.58 \\
\hline$T_{6} M_{4}$ & 18.61 & 20.10 & 38.71 & 4.95 \\
\hline $\mathbf{T}_{7} \mathbf{M}_{1}$ & 12.64 & 13.84 & 26.49 & 3.98 \\
\hline $\mathbf{T}_{7} \mathbf{M}_{2}$ & 14.01 & 15.08 & 29.09 & 4.27 \\
\hline $\mathbf{T}_{7} \mathbf{M}_{3}$ & 15.36 & 16.82 & 32.18 & 4.45 \\
\hline $\mathbf{T}_{7} \mathbf{M}_{4}$ & 17.89 & 19.01 & 36.90 & 4.78 \\
\hline SEm \pm & 1.19 & 1.04 & 2.15 & 0.20 \\
\hline $\mathrm{CD}_{(0.05)}$ & 3.31 & 2.89 & 5.99 & $\mathrm{NS}$ \\
\hline
\end{tabular}

T: Pre sowing treatments, M: Potting Mixture, NS: Non significant

Effect of pre sowing treatments on seedling growth parameters under nursery conditions

The present investigation concluded that different pre sowing treatment had a significant effect on Parkia roxburghii seedling growth parameters under nursery conditions. The seeds treated with boiling water and soaking for 24 hours produced significantly maximum root length (16.77 $\mathrm{cm})$, shoot length $(18.19 \mathrm{~cm})$, seedling length $(34.96 \mathrm{~cm})$ and collar diameter $(4.62 \mathrm{~mm})$. This may be ascribed to the fact that hot water has ability to degrade and soften the seed coat and leaching out the chemical inhibitors, which might have increased germination process and subsequent seedling growth. The result find support from Vijayakumar and Selvaraju (2013), who revealed that soaking the Cassia auriculata seeds in hot water, produced maximum root and shoot length. Jamwal et al., (2013) showed that Zizyphus mauritiana seeds soaked in water for 48 hours recorded maximum root length, seedling height and collar diameter. Similarly, Azad et al., (2011) revealed that height and diameter growth of Acacia auriculiformis seedlings originated from the seeds with hot water treatment were significantly higher than other pre sowing treatments. Soliman and Abbas (2013) concluded that the seeds of Cassia 
fistula treated with $\mathrm{H}_{2} \mathrm{SO}_{4}(36 \mathrm{~N})$ for 2 minutes and soaked in hot water $\left(100^{\circ} \mathrm{C}\right)$ produced significantly highest plant height and root length.

\section{Effect of potting mixture on Parkia roxburghii seedling growth parameters under nursery conditions}

Sowing of Parkia roxburghii seeds in the different potting mixture was found to significantly support the seedling growth. The data indicates that among different ratio of soil, sand and FYM, potting mixture consisting of soil, sand and FYM in ratio 1:2:4 $\left(\mathrm{M}_{4}\right)$ produced significantly highest root length $(16.57 \mathrm{~cm})$, shoot length $(18.02 \mathrm{~cm})$, seedling length $(34.59 \mathrm{~cm})$ and collar diameter $(4.70 \mathrm{~mm})$. The increment in growth performance is attributed to the organic carbon and nitrogen provided by organic manure.

This improves the soil physiochemical properties which further contribute to the better growth of seedlings. Bali et al., (2013) reported that optimum germination and growth for Terminallia bellirica was in silt loam soil + FYM + sunken beds combination. Chand et al., (2007) reported that seeds of Terminalia tomentosa sown in soil medium consisting of soil, sand and FYM in the ratio of $2: 1: 1$ resulted in significantly maximum seedling height, collar diameter whereas, the soil medium having soil, sand and FYM in the proportions 1:1:1 produced highest root length. Sekepe et al., (2013) reported that plant height of Cassia abbreviate was the only parameter which was significantly increased by top garden soil while other growth parameters were not influenced by growth media. Menaie et al., (2010) reported that plant height and number of leaves were higher in soil mixture which contained sand: peat-moss:humus in equal proportions (1:1:1) for Cassia nodosa and Cassia fistula seedlings. Thakur et al., (2000) found sand + soil + FYM as the best potting medium for the development of healthy seedlings with nodulated roots and better growth in Albizia lebbeck.

Interaction effect of seed size and potting mixture (LxM) on Parkia roxburghii seedling growth parameters under nursery conditions

The combined effect of seed size and potting mixture had a significant effect on seedling growth parameters. The large size seeds $\left(\mathrm{L}_{3}\right)$ sown in potting mixture consisting of soil, sand and FYM in ratio 1:2:4 $\left(\mathrm{M}_{4}\right)$ exhibited significantly maximum root length (19.93 $\mathrm{cm})$, shoot length $(21.02 \mathrm{~cm})$, seedling height $(40.95 \mathrm{~cm})$ and collar diameter $(5.11 \mathrm{~mm})$. The results find the support from the findings of Attri (2011) who concluded that large size seeds of Sapindus mukorossi sown in vermicompost and FYM @(10t/ha) produced maximum shoot length, root length, seedling height and collar diameter. Similarly, Suresha et al., (2007) recorded maximum root and shoot length of Sapindus emerginatus seedling in large size seeds sown in a mixture of sand + soil + humus (1:1:1).

Interaction effect of pre sowing treatments and potting mixture (TxM) on Parkia roxburghii seedling growth parameters under nursery conditions

In the present study, the interaction effect of pre sowing treatments and potting mixture (TXM) under nursery condition showed significant variation for seedling growth parameters. The interaction effect of pre sowing treatment and potting mixture (TXM) revealed that seeds subjected to boiling water treatment and soaking for 24 hours $\left(\mathrm{T}_{5}\right)$ and subsequent sowing in potting mixture consisting of soil, sand and FYM in ratio 1:2:4 $\left(\mathrm{M}_{4}\right)$ exhibited significantly maximum root length $(19.58 \mathrm{~cm})$, shoot length $(21.79$ $\mathrm{cm})$, seedling height $(41.37 \mathrm{~cm})$ and collar 
diameter (5.03 mm). Nath et al., (2007) reported maximum seedling growth parameters for Albizzia lebbeck seeds treated with conc. $\mathrm{H}_{2} \mathrm{SO}_{4}$ for 3 minutes and sown in growing media consisting of sawdust. Karthikeyan et al., (2006) observed similar results when used sand as germinating media. According to them germination and seedling growth were best when seeds soaked in water and germinated in sand with vermicompost which gave maximum seedling height, stem girth, root length, and percentage of germination. Hassanein (2010) reported maximum seedling growth of Bauhinia variegate and Delonix regia in scarified seeds sown in sand media.

In conclusion, Nursery studies indicated that large size seed $\mathrm{L}_{3}$ (>1.8 cm length) of Parkia roxburghii proved significantly better as compared to other seed size with respect to seedling growth. The seeds treated with boiling water and soaking for 24 hours $\left(\mathrm{T}_{5}\right)$ outclassed all other treatments. The seeds sown in potting mixture $\mathrm{M}_{4}$ (soil: sand: $\mathrm{FYM}$ in ratio 1:2:4) showed better growth than other potting mixture. The study recommends the large size seeds L3 $(>1.8 \mathrm{~cm}$ length) treated with boiling water treatment and soaking for 24 hours to break the dormancy along with potting mixture consisting of soil: sand: FYM in ratio 1:2:4 for better seedling growth.

\section{Acknowledgement}

All the authors thank Dr. N. K. Gupta (Ex. Professor and Head of Silviculture and Agroforestry Department) and Silviculture and Agroforestry Department of Dr YS Parmar University of Horticulture and Forestry for supporting this work and providing necessary facilities.

\section{References}

Athaya, C. D. (1985). Ecological studies of some forest tree seed and seed morphology. Indian Journal of Forestry, 8(1), 33-36.

Attri, V. (2011). Effect of seed size and organic manures on germination parameters and seedling biomass of Sapindus mukorossi Garten, M. Sc. Thesis, Dr. YSP UHF Nauni-Solan (H.P), India. 73 p.

Azad, M. S., Manik, M. R., Hasan, M. S., and Matin, M. A. (2011). Effect of different pre sowing treatments on seed germination percentage and growth performance of Acacia auriculiformis. Journal of Forestry Research, 22(2), 183-188.

Bali, R. S., Chauhan, D. S., and Todaria, N. P. (2013). Effect of growing media, nursery bed sand containers on seed germination and seedling establishment of Terminalia bellirica (Gaertn.) Roxb. Multipurpose tree. Tropical Ecology, 54 (1), 59-66.

Chand, T., Devar, V., and Vikas. 2007. Influence of growing media on seedling growth and biomass of laurel (Terminalia tomentosa Heyne ex Roth). Asian Journal of Soil Science, 2 (1), 83-85.

FAO. (1995). Food and Agriculture Organization, State of food and Agriculture, 1, 3-4.

Gomez, K. A. and Gomez, A. A. (1984). Statistical procedures for agricultural research. 2nd ed. John Wiley and Sons Incoporated, New York, USA.

Hassanein, A. M. A. (2010). Improving seed germination and seedling growth of some economically important trees by seed treatments and growing media. Journal of Horticultural Science and Ornamental Plants, 2 (1), 24-31.

Jamwal, M., Hussain, S., Sharma, N., and Parmar, A. M. (2013). Presowing seed treatments effect on germination and quality of rootstock in Indian ber (Zizyphus mauritiana Lam.). World Journal of Agricultural Sciences, 9(2), 116-122.

Karthikeyan, D., Jansirani, P., Balakrishanmurthy, G and Vijayakumar, A. (2006). Effect of media on seed nut germination and seedling growth of coconut (Cocos nuciferaL). Indian Coconut Journal, 37(7), 2-4.

Menaie, H. S., Ragom, O., Shatti, A., Mathew, M., and Suresh, N. (2010). Evaluating the growth performance of Cassia nodosa and Cassia fistula L. seedlings using different 
potting mixtures. Academic Journal of Plant Sciences, 3(1), 33-36.

Mwase, W. F., and Mvula, T. (2011). Effect of seed size and pre-treatment methods of Bauhinia thonningii Schum. On germination and seedling growth. African Journal of Biotechnology, 10(13), 143-148.

Nath, D. D., Rahman, M. M., Rahman, G. M. M., Islam, K. K., and Mondal, M. A. (2007). Effect of pre-treatment of seeds of Kalokoroi [Albizia lebbeck (L.) Benth.] On germination and seedling growth. Journal of Agroforestry and Environment, 1(2), 4346.

Owoh, P. W., Offiong, M. O., Udofia, S. I., and Ekanem, V. U. (2011). Effects of seed size on germination and early morphological and physiological characteristics of Gmelina arborea, Roxb. An International Multidisciplinary Journal, 5(6), 422-433.

Ponnammal, N. R., Arjunan, M. C., and Antony, K. A. (1993). Seedling growth and biomass production in Hardwickia binata Roxb. As affected by seed size. Indian Forester, 119(1), 59-62.

Rocky, P. and Sahoo, U. K. (2002). Tree bean (Parkia roxburghii G. Don) in Imphal West district of Manipur. Journal of Non-Timber Forest Products, 11(2), 135-139.

Sekepe, L., Thembinkosi, M., and Witness, M. (2013). Evaluating the growth response of Cassia abbreviata oliv. Seedlings to growing media in Botswana. Research Journal of Agriculture and Forestry Science, 1(10), 10-14.

Singh, N., and Saxena, A. K. (2009). Seed size variation and its effect on germination and seedling growth of Jatropha curcas L. Indian Forester, 135 (8), 1135-1142.
Soliman, A., and Abbas, M. S. (2013). Effects of sulfuric acid and hot water pretreatments on seed germination and seedlings growth of Cassia fistula L. American Eurasian Journal of Agriculture and Environment Science, 13(1), 07-15.

Suresha, N. L., Balachandra, H. C., and Shivanna, H. (2007). Effect of seed size on germination viability and seedling biomass in Sapindus emerginatus (Linn). Karnataka Journal of Agricultural Sciences, 20(2), 326-327.

Thakur, V., Khurana, D. K., and Thakur, I. K. (2000). Effect of potting media on seed germination and seedling growth of Albizia lebbeck (Linn.). Journal of Tree Science, 19(2), 63-65.

Thangjam, R., and Maibam, R. S. (2006). Induction of callus and somatic embryogenesis from cotyledonary explants of Parkia timoriana (DC.) multipurpose tree legume. Journal of Food, Agriculture and Environment, 4(2), 335-339.

Uniyal, A. K., Singh, B., and Todaria, N. P. (2007). Effect of seed size, sowing orientation and depth on germination and seedling growth in neem, Azadirachta indica. Seed Technology, 29, 68-75.

Venkatesh, L., Lakshmipathaiah, O. R., and Panduranga. (2010). Effect of seed size on germination, viability and seedling biomass in Sapindus emerginatus (Linn). Mysore Journal of Agricultural Sciences, 43(4), 827-829.

Vijayakumar, A. and Selvaraju, P. (2013). Standardization of seed dormancy breaking treatment in Senna (Cassia auriculata). Journal of Plant Breeding and Crop Science, 5(11): 220-223.

\section{How to cite this article:}

Aruna Rana, Chanu Langlentombi Leishangthem, Haseena Kadiri and Benjamin Ng Nakho Ziipoa. 2017. Effect of Seed Size, Pre Sowing Treatment and Potting Mixture on the Seedling Growth of Parkia roxburghii G. Don Seeds. Int.J.Curr.Microbiol.App.Sci. 6(8): 629-638. doi: https://doi.org/10.20546/ijcmas.2017.608.080 